\title{
Global distributions of world resources ${ }^{1}$
}

\author{
Caroline Guibet Lafaye ${ }^{2}$ \\ Centre Maurice Halbwachs $(C N R S)^{3}$
} Article 25: Everyone has the right to a standard of living adequate for the health and well-being of himself
and of his family, including food, clothing, housing and medical care.

Article 28: Everyone is entitled to a social and international order in which the rights and freedoms set forth in this Declaration can be fully realized. Universal Declaration of Human Rights

While the global poor are largely excluded from natural resources and condemned to watch the affluent societies sharing the abundant natural wealth of this planet amongst them, they do get their proportional share of the burdens resulting from the global economics inequality. Large parts of mankind are excluded, at the global scale, from the natural and social resources and assets of our planet. Nevertheless it seems reasonable to think that feasible paths of institutional reforms whose pursuit would substantially raise the globally worst representative share, particularly in regard to the satisfaction of standard basic needs, exist. In fact part of the macroexplanations of the economic inequalities, of the misery and oppression, involve reference to basic global institutions.

Within the national societies, the liberal theory entails a dimension of solidarity and conceives that a society is just, when it does not treat its members not only with an equal respect but also with an equal concern (Dworkin, 1985). Considering a fair global resources distribution, suppose to determine which extent this equal concern, relevant at the national level, could have at the global level. Could we extend this equal concern to the whole mankind? Could we aim for and find an integrated solution, a just and stable institutional scheme, preserving a distribution of basic rights, resources and index goods that is fair both globally and within each nation? In fact the question we would like to inquire is if the relevance of equalitarian liberal theories, at the domestic and national level, can be extended to a global scale. We would like to explore this problem firstly by an analysis of a global difference principle, secondly by an enquiry on the Pogge's Global Resource Dividend. Finally we will consider the institutional and political conditions for a globalisation of equity.

\footnotetext{
${ }^{1}$ Will be publised in J.-C. Merle (dir.), Social and Economic Justice, Dordrecht (Pays-Bas), Springer, 2009 (à paraître).

2 caroline.guibet-lafaye@ens.fr

${ }^{3}$ Centre Maurice Halbwachs (CNRS) - 48, bd Jourdan, F-75014 Paris (France).
} 


\section{1- A global difference principle}

\section{1-1 An original position global or a global original position}

Firstly it is significant that the grounds on which Rawls asserts that a fair equality of opportunity and the difference principle constitute requirements of justice militate against confining these requirements within national borders. An institutional scheme, which preserves a distribution of basic rights, resources and index goods, if constructed along Rawlsian lines, would be developed through a single unified original position global in scope. As we end up, in the framework of a closed society, with a domestic difference principle as a result of the original position, if the framework considered is the whole humanity we should encounter a global difference principle. In the Rawlsian original position global, the parties representing people of various societies - will, in a first stage $\left(\mathrm{R}_{1}\right)$ and through an implementation of the maximin, choose a criterion that makes the globally least advantaged the preeminent touchstone of global justice, no matter which societies they may belong to. Global institutions will then be assessed by how well they satisfy Rawls's criterion interpreted globally (Rawls 1971: 377-379). On a second session $\left(\mathrm{R}_{2}\right)$, the parties are conceived as "representatives of states" (Rawls 1971: 378 and 379). But $\mathrm{R}_{2}$ entails weaker constraints than $\mathrm{R}_{1}$ on international socioeconomic inequalities. Then the various nations agree to a second contract, whereby every principle of distributive justice, and especially the difference principle, is decisively rejected at the global level. Therefore the difference principle is applied only at the national level, in democratic-liberal states. In the Rawlsian view a just global basic structure needs merely to ensure that no states are too poor to be able to satisfy Rawls's criterion domestically.

By contrast if we consider not an original position global where the parties represent the people of various nations - as Rawls does - but a global original position - as Pogge does - in which all the members of the mankind are represented as individuals, we end up with a strong claim to a world resources redistribution ${ }^{4}$. In fact, some defendants of the liberal-egalitarian approach - as Beitz (1979), Pogge (1994), Van Parijs (1995), Chauvier (1999) - endeavour to understand and conceive distributive justice on a planetary scale. They aim to determine a principle of global distributive justice closer to the approach developed by Rawls in his own Theory of Justice than what Rawls judges itself appropriate at the global level. Nevertheless and at this stage, the implementation of an "international original position", imagined by Rawls, instead of a "global initial situation", in which peoples would behave as representatives, not of their nations, but of any individual in the world, in other words the application of the difference principle beyond the national borders would generate a strongly levelling redistribution of the world resources.

\footnotetext{
${ }^{4}$ Rawls recognizes only persons as "self-originating sources of valid claims" (1980: 543). Then he commits himself to base his criterion of social justice exclusively upon data about individual shares.
} 


\section{1-2 Alternatives to the difference principle}

If we consider a globalisation of the difference principle, we must examine the moral status of the natural goods (such as mineral resources, fertility, climate, etc.) within the States and in various States - because it is not enough to study the natural and social contingencies on which the international socio-economic inequalities are based or to which they are connected (Pogge 1989: §14.3). Charles Beitz for example proposes a way to use the difference principle at a global level. He suggests, deriving from the parallel between natural endowments and natural assets, a global resource redistribution principle ${ }^{5}$. One can also consider that a global difference principle may justify not merely a general adjustment of market prices but a different specification of property rights over natural assets involving, for example, an international tax on (or international ownership and control of) natural assets.

Another solution, regarding a globalized second principle, is to conceive the terms of international cooperation so that the social inequalities due to natural contingencies (the distribution of natural assets) tend to optimize the worst representative individual share (Pogge 1989: §6.4). In this way, a globalized second principle would constrain but not preclude income inequalities that reflect biased exchanges (for example, crude oil versus cotton) arising from the morally arbitrary geographical distribution of natural assets. Finally one may however suppose that a globalized difference principle is less plausible as a constraint on inequalities based upon social contingencies than a globalized difference principle based upon natural contingencies. But in all cases, how a just global institutional scheme would regulate ownership and control over natural assets depends upon the empirical question of which institutional design would optimize the worst social position.

\section{1-3 The difference principle as institutional criterion of justice}

Nevertheless some assert that in the world as it is there are special factors, relevant on the global scale but not on the national or domestic level, that make inappropriate to apply Rawls's maximin criterion to a global basic structure ${ }^{6}$. In fact, the Rawlsian conception centrally involves the claim that any self-contained social system satisfying the two principles is morally acceptable. Admittedly we are led to conclude that there is no feasible and morally viable avenue of institutional reform toward a global regime fairer and even if a fairer global basic structures are out of reach, it would not show that the Rawlsian criterion is inappropriate on the global plane because it still "can serve as a standard for appraising institutions and for guiding the overall direction of social change" (Rawls 1971: 263), to be carried "as far as circumstances permit" (Rawls 1971: 246). In any case, it seems quite impossible to deny that the position of its least advantaged participants is at least one important measure of the justice

\footnotetext{
${ }^{5}$ He wants the criterion of global justice to govern not merely the terms on which states can develop and market their natural assets but also rights over these assets themselves. But Beitz's parallel between natural assets and natural endowments, for several reasons, is mistaken (see Pogge 1989: 252).

${ }^{6}$ Bertrand Guillarme underlines that the principle of difference is reasonable when it is applied to the internal justice of the democratic societies but it does not constitute a realistic means to solve the general problem of the adverse conditions that certain societies know (1996: 84).
} 
of an institutional scheme. All we may ask is that a conception of justice provides a criterion for assessing our global order that would allow us to choose among the feasible and morally accessible paths of institutional change and thus requires from us to improve gradually the justice of this order. However a plausible evaluation of the morally significant consequences of feasible institutional schemes must give a prominent place to the satisfaction of basic social and economic needs. And this is the case even if this claim is often opposed by the assertion that it is more important that social institutions recognize and protect basic civil and political rights and liberties than they ensure that basic social and economic needs are met.

\section{2- The Global Resources Dividend (GRD)}

Even if global justice does not imply that the substantial differences of wealth which will appear through the generations are constantly levelled by a supranational institution in charge of maximizing the economic level of the worst off (see Arnsperger and Van Parijs 2003: 83), we could seek and use a distributive model in order to equilibrate the word resources inequalities. In fact who make more extensive use of the resources of our planet (that is roughly the affluent countries) should compensate those who, involuntarily, use very little. This idea does not require that we conceive global resources as the common heritage of humankind nor that they are controlled through a global democratic process and that their full value (determined through resource auctions, for example) be divided equally among all members of the human species. In this perspective T. Pogge suggests establishing a Global Resources Dividend (GRD) ${ }^{7}$. This GRD is a tax upon the use of natural resources and aims to a global distribution of the proceeds raised by this natural resources tax.

\section{2-1 Pogge's proposition}

The first point to considered is that the status quo can be reformed in a way that we would recognize as an important step in the direction of a just world order due to the fact that the existing radical inequality can be traced to the structure of our global economic order ${ }^{8}$. Precisely the GRD is grounded on a kind of difference principle: "it maintains that the most acceptable global difference principle would be the one which would most improve the conditions of the world's neediest people" (Pogge 1998: 511). This reform proposal is conceived as the first step towards implementing Pogge's version of the global difference principle among states 9 .

The GRD proposal envisions that states and their governments shall not have full libertarian property rights with respect to the natural resources in their territory, but can be

\footnotetext{
${ }^{7}$ Pogge uses word dividend partly in order to avoid the connotations of "tax" and "fee".

${ }^{8}$ Pogge suggests that an intelligent targeting of GRD liabilities makes it possible - without major changes to our global economic system - to raise a revenue stream sufficient to eradicate world hunger within a few years (Pogge 1998).
} 
required to share a small part of the value of any resources they decide to use or sell. This principle supposes a right to a share of natural resources ${ }^{10}$. Moreover the word "dividend" suggests that the global poors own an inalienable stake in all limited natural resources. This stake confers no right to participate in decisions about whether or how natural resources are to be used and therefore does not interfere with national control over resources. But it does entitle its holder to a share of the economic benefits from the use of resources considered, if they are used.

In light of the vast extent of global poverty today, one may think that a massive GRD would be necessary to solve the problem. But this is not Pogge's opinion. Firstly the initial goal could be fully achieved by targeting a limited number of resources and pollutants whose extraction or discharge is reasonably easy to monitor or estimate, in order to ensure that every society is paying its fair share and also in order to assure everyone that this is so. Initially more may be needed, that is perhaps as much as one percent of the world's social product. If radical inequalities have once been eradicated, quite a small GRD may, in the context of a fair and open world market system, be sufficient afterwards to balance those ordinary unequal tendencies of economic markets. In this view proceeds from the GRD are to be used for raising the world's minimum standard of living, in order to ensure that all human beings will be able to meet their own basic needs ${ }^{11}$. The GDR funds would enable governments to eradicate poverty in their territories in whatever way is most effective: by maintaining lowerincluding negative - tax rates, higher tax exemptions and/or higher domestic spending for education, health care, microloans, infrastructure, land reform, etc., than would otherwise be possible ${ }^{12}$.

\footnotetext{
${ }^{9}$ Pogge's declared intention with the GRD scheme is "to make an institutional proposal that virtually any plausible egalitarian conception of global justice would judge to be at least a step in the right direction" (Pogge, 1994: 199), i.e., a step in the direction of his version of the difference principle among states (cf. Pogge 1989).

${ }^{10}$ As Jean-Christophe Merle underlines it "the notion of a right to share in all natural resources is accepted both by Pogge and by Rawls, but it can be interpreted differently. Pogge understands it as 'a share of the economic benefits from the use of the resource in question' (Pogge 1998: 511). He interprets it as a right to introduce a tax upon other people's use, but it could just as easily be interpreted simply as a right to full participation. The difference is significant, since the tax on other people's use refers to a product that arises through a combination of natural resources and the work of processing them" (2005: 344). But "if we assume only a right to full participation in the use of natural resources, there is no justification for implementing a different distribution of dividends, i.e., there is no occasion for the GRD scheme. The GRD is only justified if we follow Pogge and assume not just a right to equal use of natural resources, but a right to a share in anyone's use of them" (Merle 2005: 344).

11 "Proceeds from the GRD are to be used toward the emancipation of the present and future global poor: toward assuring that all have access to education, health care, means of production (land) and/or jobs to a sufficient extent to be able to meet their own basic needs with dignity and to represent their rights and interests effectively against the rest of mankind: compatriots and foreigners" (Pogge 1994: 201). Jean-Christophe Merle notes that "this definition does not go quite as far as a genuine difference principle, since it acknowledges a threshold beyond which no redistribution occurs". "It works like a difference principle until that threshold is reached" (2005: 333).

${ }^{12}$ Nevertheless the Pogge's proposal exemplifies what J.-C. Merle calls a minimalism conception of distributive justice: "The principled minimalism of redistribution is therefore rounded out by a minimalism of means, according to which the implementation of a different distribution from the existing one would not require a central authority (see for instance Pogge 1994: 202, 224)" (2005: 330). This type of minimalism - which is false according to Merle - suggests that "distributive justice does not require the intervention of a national or an international legal order. Global distributive justice may be conceivable in the absence of a world government, but it cannot be implemented without one" (Merle 2005: 330).
} 
Finally, the GRD is supposed to satisfy two conditions which grant its implementation: a constraint of feasibility and a constraint of reality. (1) Firstly the GRD seems to be feasible: Pogge believes that this institutional alternative should be able of gaining the approval and support (especially in the wealthy countries) that is necessary to implement it. (2) Secondly the GRD should be practicable, that is able of sustaining itself (by eliciting enough cooperation and support from its participants) in the world as we know $\mathrm{it}^{13}$. It stays reasonably close to the current institutional arrangements. Finally it is obviously responsive to the moral concerns implicit in the maximization of the economic level of the worst off and in the concern for compensating or leveling unequal developments ${ }^{14}$.

\section{2-2 Conditions of the implementation of the GDR}

Nevertheless instituting a GRD would therefore require significant further institutional reforms, including central enforcement mechanisms. The Pogge's reform proposal accepts the existing state system and, in particular, leaves each national government in control of the persons and natural resources of its territory. But, according to Pogge, the entire GRD scheme would require no central bureaucracy and certainly nothing like a world government, as governments could simply transfer the GRD amounts to one another, through some facilitating organization, such as an appropriately reorganized World Bank, for example ${ }^{15}$. Nevertheless supranational institutions and organizations will be required to limit the sovereignty rights of states more severely than it is actually the case. In fact, the global reduction of inequalities suggested by Pogge "would have to be accompanied by modifications in the political and social system" (Merle 2005: 341).

\section{3- Institutional and political conditions for a globalisation of equity}

It seems thus that a radical redistribution of the world resources could not be implemented without a global government (a world government) or without a highly improbable consensus between states in order to apply such provisions. Just as Rawls requires domestic institutions to distribute whatever burdens remain in ways satisfying the second principle, the difference principle or any international redistributive mechanism should thus require international institutions to distribute such burdens analogously.

Currently the interpersonal redistribution capacity is located at the national level of the State. But this capacity could be transferred to a world State. In fact and in order to satisfy the requirements of distributive justice, the institution of a juridical and political community is absolutely necessary. For example, if there were a global state and if we consider with David

\footnotetext{
${ }^{13}$ In fact its amount is rather small for the rest of us.

${ }^{14}$ The pragmatic advantage Pogge claims for his reform proposal is that it should overcome Rawls's objections to global distributive justice, which mainly have to do with "inadequate administrative capabilities and the dangers of a world government" (1994: 199).
} 
Copp the basic needs principle ${ }^{16}$, this global state would have a duty to ensure the ability of each subordinate state to enable its members to meet their basic needs ${ }^{17}$. We can imagine, as Copp suggests, different ways to extend the basic needs principle to the case of a global federation. (1) Firstly, we could think of the global state as having the same duty with respect to enabling people to meet their needs that the individual subordinate states would have with respect to their members, if the global state didn't exist. On this view, the subordinate states are morally transparent. The global state will deal directly with the needs of individual people, just as if the subordinate states did not exist. This can be called the "transparency view". (2) Secondly, we might instead conceive that the individual subordinate states have the primary responsibility to ensure that their residents are able to meet their needs. In this view the global state is required only to ensure that the subordinate states have sufficient resources to be able to meet this primary responsibility. This can be called the "divided responsibility view" (Copp 2004: $§ 6,15)$. In both cases, this juridical community and this world state would establish a closed juridical unity, i.e. a legal community (see Merle 1997: 237) ${ }^{18}$. The divided responsibility view may be the more sensible and immediate in our world, but in different circumstances it might not be. By this way, it is possible to conceive that the global state has a duty in justice to organize a fair system for the transfer of resources from the more wealthy countries to the less well-off countries to ensure that every country comes to be in favourable circumstances (Copp 2004: $§ 7,16$ ). Therefore the subordinate countries have a duty to do their parts in implementing this system.

Although the idea of a distributive justice model on a global scale seems to involve a certain type of state organization, namely a centralized world government, this shows that we can imagine other model of world institution than a world government. First we have to avoid the confusion between sovereignty and centralization (Merle 1997: 231) ${ }^{19}$. We suppose that humanity, by becoming a single juridical community, should constitute a single state. But we can, as well, conceive a world government as a very decentralized federation. In the economic field for example, J.-C. Merle suggests considering a decentralized application of the decentralized federation model. By this way he avoids the objection of a necessary centralized authority against a world government. In a same prospect, we can conceive a world organization without a global state. The global society might be organized in a way that

\footnotetext{
${ }^{15}$ The decisions regarding the GRD funds distribution could be made, as Pogge suggests, not only through local governments, but also - or even only - through "facilitating organization" under the supervision of "an international group of economists and international lawyers".

${ }^{16}$ The "basic needs principle" requires a society to ensure that its members have access to high quality medical care, a sound basic education, decent housing, clean water, a nutritious diet, and so on.

${ }^{17} \mathrm{D}$. Copp shows also that "in the present situation, existing states have a duty (ceteris paribus) to work to create a global state or system of institutions that could discharge the global society's duty to enable people to meet their basic needs" (2004: 2).

${ }^{18}$ Merle suggests that the major objections with this model of world legal community is grounded on their applicability, i.e. on the possible transition starting from the current situation, and more precisely on the pragmatic and ethical requirements which this transition should respect.

${ }^{19}$ For example, Pogge underlines that his GDR's model accepts that "sanctions could be decentralized: Once the agency facilitating the flow of GRD payments reported that a country has not met its obligations under the scheme, all other countries would be required to impose duties on imports from, and perhaps also similar levies on exports to, this country in order to raise funds equivalent to its GRD obligations plus the cost of these enforcement measures" (Pogge 1998: 510, 517f). Nevertheless J.-C. Merle's point is that "the GRD scheme
} 
makes it able of joint actions. There could be a quasi-state. Rawls, for example, takes into account the idea of a "federative union" of states (Rawls 1999: 70). Similarly, the arguments developed by D. Copp require only the viability of a global federation or system of institutions with the capability of discharging duties regarding basic needs.

The explanatory importance of social institutions has been powerfully illustrated by numerous domestic regime changes during the history of the $\mathrm{XX}^{\text {th }}$ century. Institutional choices (e.g. between socialism and capitalism) can have an impact on the distribution of income and wealth, education and health care, rights and liberties, and hence quality of life. But being familiar with the idea on the national level has made it harder to appreciate its application on the global plane. Dramatic differences in standard of living across countries draw our attention to local factors (national institutions, cultures, resources, climates, environments, levels of development and so on). But any attempt to introduce a fairer economic system can be limited to a particular country, or a particular group of countries, because of the extent of the world inequalities and because of the context of globalisation. At the international level, it already exists certain institutions, as the World Trade Organization (WTO), the International Monetary Funds (IFM) and the World Bank, which could be used to promote economic equality and temperate the exclusive pursuit of productivity and efficiency by a greater economic safety. These organisations could thus adopt rules and implement policies, which support the equality while establishing, for example, a global minimum wage and global provisions for health and safety. Another idea, as we have seen, is to limit the economic authority of individual states by, for example, a GDR or by collecting a tax on natural resources globally and without the assent of affected countries, as Pogge suggests it. Indeed and although the realization of such changes seems currently remote, the whole economic activity is funded on norms which can be changed. As long as the development of administrative capacities and of a worldwide democracy is not encouraged and undertaken, we are condemned to satisfy ourselves with a low resources redistributive capacity at the planetary level.

\section{Bibliography}

\section{Books:}

Arnsperger, C., and Van Parijs, P., 2003, Ethique économique et sociale, La Découverte, Paris.

Beitz, C. R., 1979, Political Theory and International Relations, Princeton University Press, Princeton (New Jersey).

Chauvier, S., 1999, Justice internationale et solidarité, Jacqueline Chambon (ed.), Nîmes.

Crocker, D. A., and Linden, T., (ed.), 1998, Ethics of Consumption: The Good Life, Justice, and Global Stewardship, Rowman and Littlefield, Lanham, MD.

Dworkin, R., 1985, A Matter of Principle, Harvard University Press, Cambridge (Mass.).

Merle, J.-C., 1997, Justice et progrès, PUF, Paris.

Pogge, T. W., 1989, Realizing Rawls, Cornell University Press, Ithaca and London. 
Rawls, J., 1971, Theory of Justice, Belknap Press of Harvard University Press, Cambridge (Mass.).

Rawls, J., 1999, The Law of Peoples, Harvard University Press, Cambridge (Mass.) and London.

Rawls, J., 1996, Le droit des gens, Esprit, Paris, translation of "The Law of Peoples", On Human Rights: The Oxford Amnesty Lectures, 1993, Basic Books, New York.

Rawls, J., 1999, Collected Papers, Harvard University Press, Cambridge (Mass.) and London. Van Parijs, P., 1995, Sauver la solidarité, Le Cerf, Paris.

\section{Articles:}

Pogge, T. W., 1994, An Egalitarian Law of Peoples, Philosophy and Public Affairs 23: 195224.

Rawls, J., 1980, Kantian Constructivism in Moral Theory, Journal of Philosophy 77(9), September: 515-572.

\section{Contributions to a volume:}

Guillarme, B., 1996, Y a-t-il des principes de justice pertinents hors des frontières des régimes démocratiques ?, in: J. Rawls, Le droit des gens, Esprit, Paris.

Merle, J.-C., 2005, Can Global Distributive Justice be Minimalist and Consensual? Reflections on Thomas Pogge's Global Tax on Natural Resources, in: A. Follesdal and T. Pogge (eds.), Real World Justice: Grounds, Principles, Human Rights and Social Institutions, Kluwer, Dortrecht.

Pogge, T., 1998, A Global Resources Dividend, in: David A. Crocker and Toby Linden (ed.), Ethics of Consumption: The Good Life, Justice, and Global Stewardship, Rowman and Littlefield, Lanham, MD: 501-536.

\section{Internet:}

Copp, D., 2004, International Justice and the Basic Needs Principle, May $17^{\text {th }}$, 2004, http://mora.rente.nhh.no/projects/EqualityExchange/Manuscripts/tabid/57/Default.aspx. 